\title{
Article
}

\section{Diagnostic Interval in Extranodal Non-Hodgkin Head and Neck Lymphomas}

\author{
Alba Bello Castro ${ }^{1, *(D)}$, Juan Seoane ${ }^{1} \mathbb{D}$, Máximo Francisco Fraga Rodríguez ${ }^{2}$, Francisco Gude Sampedro ${ }^{3}$, \\ Javier Seoane Romero ${ }^{1}$, Benjamín Martin-Biedma ${ }^{1}$ and Pablo Castelo-Baz ${ }^{1}$ (D)
}

1 Department of Surgery and Medical-Surgical Specialties, School of Medicine and Dentistry, Universidade de Santiago de Compostela, Santiago de Compostela, 15705 La Coruña, Spain; juanmanuel.seoane@usc.es (J.S.); javier.seoane.romero@gmail.com (J.S.R.); b.martinbiedma@gmail.com (B.M.-B.); pablocastelobaz@hotmail.com (P.C.-B.)

2 Pathological Anatomy Unit, Universidade de Santiago de Compostela, 15705 La Coruña, Spain; maximo.fraga@usc.es

3 Unit of Clinical Epidemiology, Clinical University Hospital of Santiago de Compostela, 15705 La Coruña, Spain; francisco.gude.sampedro@sergas.es

* Correspondence: bellocastro.a@gmail.com

Citation: Castro, A.B.; Seoane, J.; Rodríguez, M.F.F.; Sampedro, F.G.; Romero, J.S.; Martin-Biedma, B.; Castelo-Baz, P. Diagnostic Interval in Extranodal Non-Hodgkin Head and Neck Lymphomas. J. Clin. Med. 2022, 11, 853. https://doi.org/10.3390/ jcm 11030853

Academic Editor: Alexandre Bozec

Received: 8 December 202

Accepted: 3 February 2022

Published: 6 February 2022

Publisher's Note: MDPI stays neutral with regard to jurisdictional claims in published maps and institutional affiliations.

Copyright: (c) 2022 by the authors Licensee MDPI, Basel, Switzerland. This article is an open access article distributed under the terms and conditions of the Creative Commons Attribution (CC BY) license (https:// creativecommons.org/licenses/by/ $4.0 /)$

\begin{abstract}
The aim of this study is to measure the diagnostic interval (DI) of primary extranodal non-Hodgkin lymphomas (PE-NHL) affecting the head and neck and to discover any associated factors. With this aim, we performed a retrospective observational study in northwestern Spain on patients diagnosed between 1 January 2005 and 1 January 2016. A search was made across the electronic health records of the public health system of this region (SERGAS). DI was used as the dependent variable, and different clinicopathological data of the corresponding patients and tumors were analyzed as exposure variables. PE-NHLs were mostly located in Waldeyer's ring, and they presented a B phenotype and had a median DI of 65 days. Shorter diagnostic intervals were observed in (1) PE-NHL patients who had comorbidities $(p=0.02)$, (2) PE-NHL that caused symptoms of dysphagia $(p=0.04)$, (3) tumors with the highest proliferative activity (Ki67 > 80\%) $(p=0.04)$, and (4) tumors diagnosed in the advanced stages of the disease $(p=0.004)$. Univariate analysis revealed a significant association between dysphagia and a shorter DI. We conclude that raising awareness about these neoplasms and warning about the presenting symptoms can contribute to earlier diagnoses of these tumors and to better outcomes.
\end{abstract}

Keywords: non-Hodgkin lymphomas; head and neck; diagnostic interval; diagnostic delay; dysphagia

\section{Introduction}

Lymphomas are solid tumors of the immune system, and among these, non-Hodgkin lymphomas (NHLs) account for $90 \%$ of the total. NHLs are a broad and heterogeneous group of neoplasms of the lymph nodes and extranodal lymphatic system produced by clonal lymphocyte proliferations [1,2]. Unlike Hodgkin lymphomas, NHLs have an erratic dissemination pattern and very variable evolutions, ranging from highly proliferative and rapidly lethal forms to indolent subtypes that are compatible with a good quality of life without treatment [1,2]. NHLs have an increasing incidence in many regions (western Europe, India, Brazil, and Japan), reaching 6.7 cases/100,000 inhabitants/year in males and 4.7 cases in females in a global (worldwide) context [2,3].

A long interval until diagnosis and treatment in symptomatic cancers (breast, colorectal, head and neck, testicular, and melanoma) seems to be associated with poor outcomes [4]. In hematological cancers, diagnostic and therapeutic delays are associated with an increase in complications, and in particular, such delays are independent prognostic factors in aggressive forms [5].Despite the fact that early diagnosis of symptomatic cancers is a worldwide priority [6], the literature on time intervals in chronic hematological malignancies is 
very scarce [7], and, specifically, the magnitude and the determining factors of the diagnostic interval ("diagnostic delay") in PE-NHL are unknown. Considering this lack of studies, our objectives were to measure the diagnostic interval in PE-NHL of the head and neck and to analyze the clinical and pathological variables associated with this time interval.

\section{Materials and Methods}

A retrospective observational study was designed to identify PE-NHLs diagnosed in Galicia (northwestern Spain) between 1 January 2005 and 1 January 2016 by searching the IANUS system (electronic records of the public health system SERGAS platform), which includes information from hospitals included in the public network of the autonomous community. This system provides healthcare to its 2,700,000 inhabitants. We also performed an active search in the clinical departments that were involved.

Primary extranodal NHLs are defined as lymphomas that are localized in the extranodal compartment. In the case of lymph node involvement, this is minor and is associated with a clinically dominant extranodal component. The patients in our study strictly met these criteria [8-10]. After staging, those classified as having stages III or IV were only deemed primary extranodal if they had minor lymph nodes and/or bone marrow involvement.

For the analysis, the following independent variables were considered: age, sex, smoking, comorbidity, presenting symptoms (symptoms reported at the presentation by the patient who was later diagnosed of PE-NHL) [11] such as B-symptoms (temperature $>38^{\circ}$, weight loss $>10 \%$ in the 6 months preceding admission, and night sweats), the number of involved sites, histological subtypes of NHL [12,13], Ki-67 (as a cell proliferation factor $\geq 80 \%$ vs. $<80 \%$ ), stage (Ann Arbor staging system) [14], Eastern Cooperative Oncology Group (ECOG) performance status [15], and International Prognostic Index (IPI) for NHL [4].

The diagnostic interval (the date of the first symptom/sign until the date of histological diagnosis) was considered as a dependent variable in the model of pathways to treatment [16]. The investigation was carried out with the authorization of the Research Ethics Committee of the Xunta de Galicia (CEIm-G) with the code MFR-RIT-2018-01 (2018/596) and was in full accordance with the Declaration of Helsinki.

\section{Statistical Analysis}

Single-variable descriptive analysis was performed using frequencies for qualitative variables and using the mean (standard deviation), the median (interquartile range), and the 90th percentile for quantitative variables. The non-parametric Mann-Whitney $U$ and Kruskal-Wallis tests were used in order to compare the differences in time to diagnosis according to tumor and patient baseline characteristics.

By using the median as a cutting point, we dichotomized the variable "time to diagnosis" as either a short time to diagnosis ( $<65$ days) or a long time to diagnosis ( $>65$ days). Thereafter, a univariate analysis was performed applying logistic regression using the dichotomized variable as a dependent variable. Moreover, a multivariate logistic regression was made using the diagnosis interval (DI) as a dependent variable.

\section{Results}

A total of 139 patients diagnosed with symptomatic PE-NHL met the inclusion criteria in the study with a male/female ratio of 1.01 and a mean age of $67.5 \pm 16.8$ years. The median diagnostic interval for the sample was 65 days (IQR, 32-119).

A total of 131 patients $(94 \%)$ were in a good clinical condition (ECOG performance score: $0-1$ ), and $57 \%$ of cases were categorized into a low-risk prognostic group (IPI score: $0-1$ ), $36-50 \%$ of cases had an intermediate risk (IPI score: $2-3$ ), and only $6 \%$ of cases were classified as having high risk (IPI score: $4-5)$. A total of 36 patients $(26 \%)$, had associated comorbidity and $8(6 \%)$ were HIV+ patients. Patient characteristics are summarized in Table 1. 
Table 1. Comparison of diagnostic intervals according to patient characteristics.

\begin{tabular}{|c|c|c|c|c|c|}
\hline \multicolumn{2}{|c|}{ Extranodal NHL } & \multicolumn{4}{|c|}{ Diagnostic Interval } \\
\hline Variable & $N(\%)$ & Mean (SD) & $\begin{array}{c}\text { Median } \\
\text { (Interquartile } \\
\text { Range) }\end{array}$ & $90 \%$ & $p$-Value \\
\hline \multicolumn{6}{|c|}{ Age } \\
\hline$<60$ & $40(29 \%)$ & $135(29)$ & $83(33-172)$ & 299 & \multirow{2}{*}{0.198} \\
\hline$\geq 60$ & $95(68 \%)$ & $95(11)$ & $61(31-104)$ & 226 & \\
\hline \multicolumn{6}{|c|}{ Gender } \\
\hline Male & $70(50.4 \%)$ & $95(13)$ & $62(26-117)$ & 255 & \multirow{2}{*}{0.308} \\
\hline Female & $69(49.6 \%)$ & $118(19)$ & $68(37-138)$ & 244 & \\
\hline \multicolumn{6}{|c|}{ Tobacco } \\
\hline Smoker & $109(78.4 \%)$ & $104(13)$ & $62(32-116)$ & 238 & \multirow{3}{*}{0.843} \\
\hline Non-Smoker & $18(13.9 \%)$ & $108(24)$ & $70(28-151)$ & 300 & \\
\hline Former smoker & $12(8.6 \%)$ & $128(43)$ & $98(32-160)$ & 457 & \\
\hline \multicolumn{6}{|c|}{ Comorbidity } \\
\hline No & $103(74 \%)$ & $117(15)$ & $69(32-135)$ & 302 & \multirow{2}{*}{0.027 * } \\
\hline Yes & $36(26 \%)$ & $76(11)$ & $57(31-117)$ & 181 & \\
\hline \multicolumn{6}{|c|}{ Neoplasm } \\
\hline No & $116(83.5 \%)$ & $113(13)$ & $69(32-129)$ & 283 & \multirow{2}{*}{0.054} \\
\hline Yes & $23(16.5 \%)$ & $74(15)$ & $53(22-103)$ & 211 & \\
\hline \multicolumn{6}{|c|}{$\mathrm{B} / \mathrm{C}$ hepatitis } \\
\hline No & $128(92 \%)$ & $107(12)$ & $63(31-117)$ & 263 & \multirow{2}{*}{0.614} \\
\hline Yes & $11(8 \%)$ & $97(16)$ & $115(51-122)$ & 187 & \\
\hline \multicolumn{6}{|c|}{ HIV } \\
\hline No & $131(94 \%)$ & $108(12)$ & $63(32-120)$ & 258 & \multirow{2}{*}{0.164} \\
\hline Yes & $8(6 \%)$ & 78 (17) & $91(26-120)$ & & \\
\hline \multicolumn{6}{|c|}{ B symptoms } \\
\hline No & $112(80.5 \%)$ & 109(13) & $69(32-120)$ & 242 & \multirow{2}{*}{0.648} \\
\hline Yes & $27(19.5 \%)$ & $98(21)$ & $48(31-122)$ & 283 & \\
\hline \multicolumn{6}{|c|}{ LDH } \\
\hline Normal & $93(67 \%)$ & $106(15)$ & $62(31-118)$ & 238 & \multirow{2}{*}{0.931} \\
\hline High & $30(22 \%)$ & $109(20)$ & $56(31-164)$ & 275 & \\
\hline \multicolumn{6}{|c|}{ ECOG } \\
\hline $0-1$ & $131(94 \%)$ & $107(12)$ & $63(32-120)$ & 243 & \multirow{2}{*}{0.998} \\
\hline$(2-3)$ and $(4-5)$ & $8(6 \%)$ & $107(32)$ & $97(28-178)$ & & \\
\hline \multicolumn{6}{|c|}{ IPI } \\
\hline 0 & $79(57 \%)$ & 118 (17) & $71(36-133)$ & 297 & \multirow{3}{*}{0.547} \\
\hline 1 & $50(36 \%)$ & 91 (15) & $48(31-107)$ & 239 & \\
\hline 2 & $8(6 \%)$ & $112(30)$ & $90(41-178)$ & & \\
\hline
\end{tabular}

LDH: lactate dehydrogenase; ECOG: Eastern Cooperative Oncology Group; IPI: International Prognostic Index *: statistically significant.

PE-NHLs were preferentially located in Waldeyer's ring (47.5\%) and in salivary glands $(24.5 \%)$. The most common presenting symptoms were swelling $(52.5 \%)$ along with pain 
(20\%). Extranodal masses were measured to have a diameter of $36 \mathrm{~mm}$ (34-101) at the time of diagnosis, although only six patients $(4.3 \%)$ had a bulky mass ( $>70 \mathrm{~mm}$ in diameter). The vast majority $(91.7 \%)$ had a B phenotype, and Diffuse B-Large Cell Lymphomas (DLBCL) accounted for $58 \%$ of the sample. The characteristics of PE-NHL are summarized in Table 2.

Table 2. Comparison of diagnostic intervals according to tumor characteristics.

\begin{tabular}{|c|c|c|c|c|c|}
\hline $\begin{array}{c}\text { Extranodal } \\
\text { Non-Hodgkin }\end{array}$ & \multicolumn{5}{|c|}{ Diagnostic Interval } \\
\hline Variable & $\mathbf{N}(\%)$ & Mean (SD) & $\begin{array}{c}\text { Median } \\
\text { (Intercuartil } \\
\text { Range) }\end{array}$ & $\begin{array}{c}\text { 90th } \\
\text { Centile }\end{array}$ & $p$-Value \\
\hline \multicolumn{6}{|c|}{ Symptoms } \\
\hline Swelling & $73(52.5 \%)$ & $113(14)$ & $76(33-127)$ & 302 & \multirow{6}{*}{$0.049 *$} \\
\hline Pain & $28(20 \%)$ & $102(23)$ & $43(27-139)$ & 293 & \\
\hline Dysphagia & $20(14.5 \%)$ & $63(12)$ & $45(31-74)$ & 191 & \\
\hline Nasal irritation & $9(6.5 \%)$ & $95(18)$ & $92(54-134)$ & & \\
\hline Lymphadenopathy & $5(3.5 \%)$ & $83(42)$ & $59(20-158)$ & & \\
\hline Odynophagia & $4(3 \%)$ & $302(255)$ & $59(26-821)$ & & \\
\hline \multicolumn{6}{|c|}{ Sites } \\
\hline Waldeyer's ring (ref) & $66(47.5 \%)$ & $100(19)$ & $59(31-102)$ & 250 & \multirow{4}{*}{0.383} \\
\hline Nasal cavity/maxilar & $23(16.5 \%)$ & $99(21)$ & $62(29-135)$ & 238 & \\
\hline Oral cavity & $16(11.5 \%)$ & $75(20)$ & $37(23-111)$ & 229 & \\
\hline Glands & $34(24.5 \%)$ & $139(23)$ & $100(57-173)$ & 357 & \\
\hline \multicolumn{6}{|c|}{ Size } \\
\hline$<36 \mathrm{~mm}$ & $68(49 \%)$ & $129(20)$ & $76(34-172)$ & 308 & \multirow{2}{*}{0.061} \\
\hline$\geq 36 \mathrm{~mm}$ & $66(48 \%)$ & $86(12)$ & $57(28-101)$ & 182 & \\
\hline \multicolumn{6}{|c|}{ Stage } \\
\hline (I-II) & $95(68.3 \%)$ & $124(16)$ & $72(36-140)$ & 315 & \multirow{2}{*}{$0.004^{*}$} \\
\hline (III-IV) & $43(30.9 \%)$ & $69(10)$ & $47(25-104)$ & 171 & \\
\hline \multicolumn{6}{|c|}{ Histology } \\
\hline DLBCL (ref) & $80(58 \%)$ & $86(10)$ & $59(31-103)$ & 173 & \multirow{6}{*}{0.085} \\
\hline FL & $16(12.5 \%)$ & $83(21)$ & $56(31-106)$ & 241 & \\
\hline MCL & $19(14 \%)$ & $164(56)$ & $94(34-219)$ & 417 & \\
\hline NKL & $9(6,5 \%)$ & $157(61)$ & $89(26-267)$ & & \\
\hline MALT & $11(8 \%)$ & $165(42)$ & 135 (51-277) & 431 & \\
\hline Otros & $4(3 \%)$ & $66(23)$ & $66(25-109)$ & & \\
\hline \multicolumn{6}{|c|}{ Ki67 } \\
\hline$<80$ & $40(29 \%)$ & $140(29)$ & $94(37-190)$ & 259 & \multirow{2}{*}{$0.048^{*}$} \\
\hline$\geq 80$ & $50(36 \%)$ & $79(13)$ & $47(21-105)$ & 172 & \\
\hline
\end{tabular}

DLBCL: Diffuse large B-cell lymphoma; FL: Follicular Lymphoma; MCL: Mantle cell lymphoma; NKL: Natural Killer Lymphoma; MALT: mucosa-associated lymphoid tissue; *: statistically significant.

Some patient subgroups presented shorter diagnostic intervals (Tables 1 and 2). These were: (1) PE-NHL patients who had comorbidities $(p=0.02),(2)$ those cases with dysphagia as presenting symptoms $(p=0.04),(3)$ tumors with the highest proliferative activity $(\mathrm{Ki67}>80 \%)(p=0.04)$, and (4) those diagnosed at advanced stages of the disease $(p=0.004)$. 
Univariate regression unveiled a significant association between DI and presenting symptoms, such as dysphagia ( $\mathrm{HR}=0.206,95 \%$ CI $0.063-0.677)$, but not between DI and any of the following: the Ki-67 value, NHL stage, comorbidity, age, sex, tobacco consumption, associated pathology, presence of B-symptoms, raised LDH, ECOG performance status, IPI score, the number of involved sites, tumor size or histological subtypes (Table 3).

Table 3. Univariate analysis of related factors with shorter diagnosis interval.

\begin{tabular}{|c|c|c|c|c|c|c|}
\hline Model & Components & B & SE & Wald & $p$-Value & $\begin{array}{c}\text { OR } \\
\text { (C.I 95\%) }\end{array}$ \\
\hline Interval-age & $\geq 60$ & -0.492 & 0.381 & 1.67 & 0.196 & $0.611(0.290-1.288)$ \\
\hline $\begin{array}{l}\text { Interval- } \\
\text { gender }\end{array}$ & Female & 0.433 & 0.341 & 1.611 & 0.204 & $1.542(0.709-3.010)$ \\
\hline \multirow{2}{*}{$\begin{array}{l}\text { Interval- } \\
\text { tabaco }\end{array}$} & Non-smoker & -0.581 & 0.520 & 1.246 & 0.264 & $0.560(0.202-1.551)$ \\
\hline & Former smoker & -0.822 & 0.642 & 1.640 & 0.200 & $0.440(0.125-1.547)$ \\
\hline $\begin{array}{c}\text { Interval- } \\
\text { comorbidity }\end{array}$ & Comorbidity & 0.019 & 0.387 & 0.003 & 0.960 & $1.020(0.477-2.178)$ \\
\hline $\begin{array}{l}\text { Interval- } \\
\text { neoplasm }\end{array}$ & Neoplasm & -0.511 & 0.466 & 1.202 & 0.273 & $0.600(0.241-1.495)$ \\
\hline $\begin{array}{c}\text { Interval-B/C } \\
\text { hepatitis }\end{array}$ & B/C Hepatitis & 0.622 & 0.651 & 0.913 & 0.339 & $1.863(0.520-6.676)$ \\
\hline Interval-HIV & HIV & 1.175 & 0.835 & 1.980 & 0.159 & $3.238(0.630-16.636)$ \\
\hline $\begin{array}{l}\text { Interval- B } \\
\text { symptoms }\end{array}$ & B symptoms & -0.872 & 0.450 & 3.754 & 0.053 & $0.418(0.173-1.010)$ \\
\hline Interval-LDH & $\mathrm{LDH} \geq 418 \mathrm{u} / \mathrm{L}$ & 0.247 & 0.423 & 0.341 & 0.559 & $1.280(0.559-2.931)$ \\
\hline $\begin{array}{l}\text { Interval- } \\
\text { ECOG }\end{array}$ & $\mathrm{ECOG} \geq 2$ & 0.015 & 0.728 & 0.000 & 0.983 & $1.015(0.244-4.233)$ \\
\hline \multirow{2}{*}{ Interval-IPI } & IPI 1 & 0.500 & 0.365 & 1.881 & 0.170 & $1.649(0.807-3.372)$ \\
\hline & IPI 2 & 0.178 & 0.742 & 0.057 & 0.811 & $1.194(0.279-5.117)$ \\
\hline \multirow{6}{*}{$\begin{array}{c}\text { Interval- } \\
\text { symptoms }\end{array}$} & Swelling & 0.192 & 0.235 & 0.669 & 0.413 & $1.212(-)$ \\
\hline & Pain & 0.095 & 0.448 & 0.45 & 0.832 & $1.1(0.457-2.649)$ \\
\hline & Dysphagia & -1.579 & 0.606 & 6.776 & $0.009 *$ & $0.206(0.063-0.677)$ \\
\hline & Nasal irritation & -0.416 & 0.711 & 0.342 & 0.559 & $0.660(0.164-2.658)$ \\
\hline & Lymphadenopathy & -0.598 & 0.943 & 0.402 & 0.526 & $0.550(0.087-3.490)$ \\
\hline & Odynophagia & 0.906 & 1.178 & 0.591 & 0.442 & $2.475(0.246-24.925)$ \\
\hline \multirow{3}{*}{$\begin{array}{l}\text { Interval- } \\
\text { location }\end{array}$} & Nasal cavity & 0.685 & 0.494 & 1.925 & 0.165 & $1.985(0.754-5.226)$ \\
\hline & Oral cavity & 0.244 & 0.558 & 0.191 & 0.662 & $1.276(0.427-3.810)$ \\
\hline & Glands & 0.361 & 0.424 & 0.727 & 0.394 & $1.435(0.626-3.293)$ \\
\hline Interval-size & $\geq 36 \mathrm{~mm}$ & 0.359 & 0.347 & 1.072 & 0.300 & $1.432(0.726-2.827)$ \\
\hline Interval-stage & III-IV & 0.476 & 0.371 & 1.644 & 0.200 & $1.619(0.778-3.333)$ \\
\hline \multirow{6}{*}{$\begin{array}{l}\text { Interval- } \\
\text { histology }\end{array}$} & DLBCL & 0.150 & 0.224 & 0.449 & 0.503 & $1.162(-)$ \\
\hline & $\mathrm{MCL}$ & -0.402 & 0.552 & 0.530 & 0.467 & $0.669(0.227-1.973)$ \\
\hline & FL & -0.469 & 0.516 & 0.825 & 0.364 & $0.626(0.228-1.720)$ \\
\hline & NKL & -0.373 & 0.707 & 0.279 & 0.598 & $0.688(0.172-2.753)$ \\
\hline & MALT & 0.032 & 0.646 & 0.002 & 0.960 & $1.033(0.291-3.661)$ \\
\hline & Other & -1.249 & 1.176 & 1.127 & 0.288 & $0.287(0.029-2.876)$ \\
\hline Ki67 & $\geq 80$ & -0.100 & 0.425 & 0.056 & 0.814 & $0.905(0.394-2.079)$ \\
\hline
\end{tabular}

LDH: lactate dehydrogenase; ECOG: Eastern Cooperative Oncology Group; IPI: International Prognostic Index DLBCL: Diffuse large B-cell lymphoma; FL: Follicular Lymphoma; MCL: Mantle cell lymphoma; NKL: Natural Killer/T-cell Lymphoma; MALT: mucosa-associated lymphoid tissue; *: statistically significant.

Additionally, we noted a significant association between DI and the presenting symptoms in the multivariate regression (Table 4). 
Table 4. Multivariate analysis of related factors with shorter diagnosis interval.

\begin{tabular}{cccccc}
\hline Model & B & $\begin{array}{c}\text { Standard } \\
\text { Error }\end{array}$ & Wald & $p$-Value & $\begin{array}{c}\text { OR } \\
\text { (C.I 95\%) }\end{array}$ \\
\hline Reference & -0.818 & 0.625 & 1.715 & 0.190 & $0.441(-)$ \\
\hline Stage & 0.259 & 0.490 & 0.279 & 0.598 & $1.295(0.495-3.388)$ \\
\hline Symptoms & 1.134 & 0.467 & 5.903 & $0.015^{*}$ & $3.107(1.245-7.754)$ \\
\hline Localization & 0.349 & 0.461 & 0.517 & 0.450 & $1.417(0.574-3.502)$ \\
\hline Morbidity & -0.384 & 0.514 & 0.557 & 0.455 & $0.681(0.248-1.867)$ \\
\hline Ki67 & -0.035 & 0.456 & 0.006 & 0.938 & $0.965(0.395-2.358)$ \\
\hline * statistically significant. & & & &
\end{tabular}

\section{Discussion}

\section{Study Limitations and Strengths}

As with any study, there are some weaknesses that must be taken into consideration for adequate interpretation of our data. These points are: (1) differences in geographical distribution of the different NHL subtypes, (2) a potential recall bias, and (3) potential misclassification.

For the first point, epidemiologic data indicate the existence of remarkable differences in the incidence of some NHL subtypes between geographical locations and race; therefore, the extrapolation of data from our cohort should be performed cautiously, particularly to regions with a non-Caucasic population [2].

Based on the retrospective nature of the study, a potential recall bias should be assumed, which could compromise the information recalled by the patients. However, this bias could also affect prospective diagnostic delay designs, as a random design is not possible for ethical reasons. In order to minimize this potential information bias, hospital data were checked against primary healthcare records, which are based on symptom information that is less prone to memory bias than self-reported information [11].

Furthermore, the diagnostic interval could be subject to differential misclassification; non-random recalling of dates when symptoms are vague occurs in indolent forms of PE-NHL. Our observational study included a large patient sample recruited with a high inclusion rate $(94.4 \%)$, making the presence of selection biases unlikely. However, the fact that researchers involved in the design of the study had also undertaken data retrieval tasks may have resulted in an information bias, but the type of data used in our study and the retrospective nature of our investigation makes the existence of this particular systematic error highly unlikely.

Among the strengths of the analysis, it should be noted that a wide multicenter sample was analyzed, which is highly representative of the study population. Furthermore, restrictive criteria in the case definition (PE-NHL) were used, which avoids misclassifications associated with the use of liberal criteria of PE-NHL [17]. The definitions of time points and diagnostic intervals of the model of pathways to treatment (the Aarhus statement) as well as the requirements of the Aarhus checklist used to estimate the date of the first symptom and the date of the diagnosis [16] have also been followed. In addition, regression analysis has been carried out to control for confounding factors associated with observational studies.

A higher burden of comorbidities has been shown to behave as a diagnostic delay predictor in DLBCLs. However, potential DI inaccuracies must be assumed in the context of comorbid conditions [11,15].

Presenting symptoms of hematological malignancies are usually vague and nonspecific, with a broad symptom signature and diagnostic difficulty [11]. Specifically, lymphomas are considered to be of intermediate diagnostic difficulty, and patients usually undergo multiple primary care consultations prior to diagnosis, thereby lengthening the diagnostic time interval [11]. The few available studies, focused on NHLs at any location, are of European origin and found a median DI in a range of 51 to 132 days [5,7]. Meanwhile, 
the only head and neck NHL study, which considered extranodal lymphomas, showed a median DI of 90 days, which is far higher than that found for PE-NHLs in this series.

According to our data, lymphoma histological grade plays a key role in diagnostic delay, with aggressive tumors such as DLBCL being more prone to be diagnosed earlier than low-grade tumors, which can have an indolent course and might be easily confounded with benign lesions. Indeed, we observed a shorter DI associated with tumors with higher proliferative activity (Ki67 > 80\%), which is consistent with similar reports of NHL affecting other anatomic locations and of PE-NHL affecting the head and neck [18]. Furthermore, the subtypes with greater clinical aggressiveness included in our series (e.g., DLBCL) presented a lower DI than mucosa-associated lymphoid tissue (MALT) lymphomas and Follicular Lymphomas, which usually follow an indolent course. This same distribution has also been observed for NHL from other locations [19].

Presenting symptoms in our series determine the diagnostic interval. Particularly, the following symptoms provided an earlier diagnosis: dysphagia and pain of the NHLs of Waldeyer's ring, observable tumors in the oral cavity, and the presence of B-symptoms, whereas nonspecific symptoms generated by the sinonasal lymphomas provide the greatest intervals until diagnosis [5,7]. These findings are consistent with what happens in different types of lymphomas in different locations $[5,7,15]$.

In concordance with our series, different neoplasms, such as breast, lung, colorectal, ovarian, and oral cancer, have shown a paradoxical association between shorter diagnostic intervals and having an advanced stage at diagnosis [20]. This counterintuitive association seems to be justified by indication confounders (waiting time paradox) where professionals prioritize severely ill patients for diagnosis and where the most proliferative tumors are the ones that have shown the fewest intervals until diagnosis.

The hematimetry findings were not relevant and do not appear to contribute to diagnostic suspicion, probably due to the extranodal nature of NHL in our series, which excluded patients with significant lymph node involvement and/or bone marrow infiltration. In contrast, hypogammaglobulinemia appeared to be more common in indolent NHL, and the elevation of markers of proliferation such as LDH and beta2-microglobulin [21] in biochemical analysis appeared in a quarter of cases. Thus, in the extranodal tumors in the head and neck, the elevation of LDH suggests the presence of pathology of lymphoid origin and a high degree of aggressiveness.

\section{Implications for Clinicians and Researchers}

The head and neck PE-NHLs have few specific symptoms and are dependent on the histological subtype and tumor location, which is the reason why they generate a low diagnostic suspicion and wide temporal intervals until definitive diagnosis ("diagnostic delays"). These circumstances and the heterogeneous clinical presentation of NHLs represent a diagnostic challenge for ENT specialists.

Signs and symptoms of PE-NHL may be similar to that of squamous cell carcinomas of the head and neck, and they are only histologically differentiable [17]. In the case of PE-NHL, the symptomatology is very dependent on the location and aggressiveness of the histological subtype [22]. In our series, frequent involvement of Waldeyer's ring and the oral cavity by aggressive subtypes (clear predominance of DLBCL) conditioned the shortest diagnostic intervals. By contrast, PE-NHLs, which had more trivial symptoms and glandular seating, were histologically associated with a high proportion of low-grade B lymphomas (MALT and follicular lymphomas), representing the greatest "diagnostic delays". Based on the above, in order to achieve an early diagnosis and better outcomes, it seems necessary to increase our diagnostic suspicion towards this neoplasm and to use wellestablished clinical protocols. In the case of NHLs, the use of algorithms of a recommended diagnostic workup has been suggested, including the careful endoscopic examination of upper cavities, a deep biopsy of extranodal diseases, blood analysis (LDH level, HIV serology, CD4+ cell count, etc.), and complementary examinations (orthopantomography, 
CT-Scan, MRI, etc.) [23,24]. Particularly, this awareness should be applied to risk groups associated with long diagnostic intervals.

Future research is also necessary to develop strategies based on the early diagnosis of symptomatic NHLs in the head and neck. For this purpose, multicenter studies should be designed which consider the ethnicity and geographic area of the sample that has a clear case definition and that follows the conceptual framework (model of pathways to treatment) and the standards of the Aarhus Declaration developed for improved design on early cancer diagnosis.

\section{Conclusions}

Head and neck PE-NHLs have a heterogeneous clinicopathological presentation with different presenting symptoms, although their B phenotypes and their locations in Waldeyer's ring predominate. Dysphagia behaves similar to an "alarm symptom" and appears to be associated with earlier diagnoses (shorter DI). However, the interval to diagnosis shows a wide space for improvement. Raising awareness about these neoplasms and warning about any presenting symptoms can contribute to obtaining early diagnoses and better outcomes.

Author Contributions: A.B.C., M.F.F.R. and F.G.S.; Formal analysis, A.B.C., F.G.S. and P.C.-B.; Investigation, A.B.C., M.F.F.R., J.S.R. and P.C.-B.; Methodology, A.B.C., J.S., F.G.S., B.M.-B. and P.C.-B.; Project administration, A.B.C.; Supervision, J.S., M.F.F.R., F.G.S. and B.M.-B.; Validation, J.S.R.; Writingoriginal draft, A.B.C., J.S. and P.C.-B. All authors have read and agreed to the published version of the manuscript.

Funding: For this study, any type of financing has been received.

Institutional Review Board Statement: This study was approved by the Institutional Review Board from Santiago-Lugo on with the following code.

Informed Consent Statement: Patietn consent was waived after approval by the institutional review board. Data was anonymyzed.

Data Availability Statement: Data can be shared upon request.

Conflicts of Interest: The authors declare no conflict of interest.

\section{Abbreviations}

$\begin{array}{ll}\text { DI } & \text { Diagnosis Interval } \\ \text { DLBCL } & \text { Diffuse Large B-cell Lymphoma } \\ \text { ECOG } & \text { Eastern Cooperative Oncology Group } \\ \text { ENT } & \text { Ear, Nose and Throat } \\ \text { FL } & \text { Follicular Lymphoma } \\ \text { HIV } & \text { Human Immunodeficiency Virus } \\ \text { IPI } & \text { International Prognostic Index } \\ \text { IQR } & \text { Interquartile Range } \\ \text { LDH } & \text { Lactate Dehydrogenase } \\ \text { MALT } & \text { Mucous Associated Lymphoid Tissue Lymphoma } \\ \text { MCL } & \text { Mantle Cell Lymphoma } \\ \text { NHL } & \text { Non-Hodgkin Lymphoma } \\ \text { NKL } & \text { NK-T cell Lymphomas } \\ \text { PE-NHL } & \text { Primary Extranodal Non-Hodgkin Lymphoma }\end{array}$

\section{References}

1. A clinical evaluation of the International Lymphoma Study Group classification of non-Hodgkin's lymphoma. The Non-Hodgkin's Lymphoma Classification Project. Blood 1997, 89, 3909-3918. [CrossRef]

2. Shankland, K.R.; Armitage, J.O.; Hancock, B.W. Non-Hodgkin lymphoma. Lancet 2012, 380, 848-857. [CrossRef]

3. New Global Cancer Data: GLOBOCAN 2018. Available online: https://www.iccp-portal.org/news/globocan-2018 (accessed on 7 December 2021). 
4. International Non-Hodgkin's Lymphoma Prognostic Factors Project. A predictive model for aggressive non-Hodgkin's lymphoma. N. Eng. J. Med. 1993, 329, 987-994. [CrossRef]

5. Allgar, V.L.; Neal, R.D. Delays in the diagnosis of six cancers: Analysis of data from the National Survey of NHS Patients: Cancer Br. J. Cancer 2005, 92, 1959-1970. [CrossRef]

6. Neal, R.D. Do diagnostic delays in cancer matter? Br. J. Cancer 2009, 101 (Suppl. 2), S9-S12. Available online: https://www. nature.com/articles/6605384 (accessed on 7 December 2021). [CrossRef]

7. Abel, G.A.; Friese, C.R.; Magazu, L.S.; Richardson, L.C.; Fernandez, M.E.; De Zengotita, J.J.; Earle, C.C. Delays in referral and diagnosis for chronic hematologic malignancies: A literature review. Leuk. Lymphoma. 2008, 49, 1352-1359. [CrossRef]

8. D'Amore, F.; Christensen, B.E.; Brincker, H.; Pedersen, N.T.; Thorling, K.; Hastrup, J.; Pedersen, M.; Jensen, M.K.; Johansen, P.; Andersen, E. Clinicopathological features and prognostic factors in extranodal non-Hodgkin lymphomas. Danish LYFO Study Group. Eur. J. Cancer 1991, 27, 1201-1208. [CrossRef]

9. Dawson, I.M.; Cornes, J.S.; Morson, B.C. Primary malignant lymphoid tumours of the intestinal tract. Report of 37 cases with a study of factors influencing prognosis. Br. J. Surg. 1961, 49, 80-89. Available online: https://academic.oup.com/bjs/articleabstract/49/213/80/6234451?redirectedFrom=fulltext (accessed on 7 December 2021). [CrossRef]

10. Herrmann, R.; Panahon, A.M.; Barcos, M.P.; Walsh, D.; Stutzman, L. Gastrointestinal involvement in non-Hodgkin's lymphoma Cancer 1980, 46, 215-222. Available online: https:/ / acsjournals.onlinelibrary.wiley.com/doi/10.1002/1097-0142(19800701)46: 1\%3C215::AID-CNCR2820460136\%3E3.0.CO;2-6 (accessed on 7 December 2021). [CrossRef]

11. Lyratzopoulos, G.; Saunders, C.L.; Abel, G.A.; McPhail, S.; Neal, R.D.; Wardle, J.; Rubin, G.P. The relative length of the patient and the primary care interval in patients with 28 common and rarer cancers. Br. J. Cancer 2015, 112, 35-40. [CrossRef]

12. Campo, E.; Swerdlow, S.H.; Harris, N.L.; Pileri, S.; Stein, H.; Jaffe, E.S. The 2008 WHO classification of lymphoid neoplasms and beyond: Evolving concepts and practical applications. Blood 2011, 117, 5019-5032. [CrossRef]

13. Swerdlow, S.H.; Elias Campo, E.; Pileri, S.A.; Harris, N.L.; Stein, H.; Siebert, R.; Advani, R.; Ghielmini, M.; Salles, G.A.; Zelenetz, A.D.; et al. The 2016 Revision of the World Health Organization classification of lymphoid neoplasms. Blood 2016, 127, 2375-2390. [CrossRef]

14. Carbone, P.P.; Kaplan, H.S.; Musshoff, K.; Smithers, D.W.; Tubiana, M. Report of the Committee on Hodgkin's Disease Staging Classification. Cancer Res. 1971, 31, pp. 1860-1861. Available online: https:/ / cancerres.aacrjournals.org/content/canres/31/11/ 1860.full.pdf (accessed on 7 December 2021).

15. Nikonova, A.; Guirguis, H.R.; Buckstein, R.; Cheung, M.C. Predictors of delay in diagnosis and treatment in diffuse large B-cell lymphoma and impact on survival. Br. J. Haematol. 2015, 168, 492-500. [CrossRef]

16. Weller, D.; Vedsted, P.; Rubin, G.; Walter, F.M.; Emery, J.; Scott, S.; Campbell, C.; Andersen, R.S.; Hamilton, W.; Olesen, F.; et al. The Aarhus statement: Improving design and reporting of studies on early cancer diagnosis. Br. J. Cancer 2012, 106, 1262-1267. [CrossRef]

17. Zucca, E.; Roggero, E.; Bertoni, F.; Conconi, A.; Cavalli, F. Primary extranodal non-Hodgkin's lymphomas. Part 2: Head and neck, central nervous system and other less common sites. Ann. Oncol. 1999, 10, 1023-1033. [CrossRef]

18. Summerfield, G.P.; Carey, P.J.; Galloway, M.J.; Tinegate, H.N. An audit of delays in diagnosis and treatment of lymphoma in district hospitals in the northern region of the United Kingdom. Clin. Lab. Haematol. 2000, 22, 157-160. [CrossRef]

19. Howell, R.E.; Wright, B.A.; Dewar, R. Trends in the incidence of oral cancer in Nova Scotia from 1983 to 1997. Oral Surg. Oral Med. Oral Pathol. Oral Radiol. Endod. 2003, 95, 205-212. [CrossRef]

20. Seoane, J.; Takkouche, B.; Varela-Centelles, P.; Tomás, I.; Seoane-Romero, J.M. Impact of delay in diagnosis on survival to head and neck carcinomas: A systematic review with meta-analysis. Clin. Otolaryngol. 2012, 37, 99-106. [CrossRef]

21. Freedman, A.S.; Friedberg, J.W.; Aster, J.C. Clinical presentation and diagnosis of non-Hodgkin lymphoma. UpToDate 2020. E-collection.

22. van der Waal, R.I.; Huijgens, P.C.; van der Valk, P.; van der Waal, I. Characteristics of 40 primary extranodal non-Hodgkin lymphomas of the oral cavity in perspective of the new WHO classification and the International Prognostic Index. Inter. J. Oral. Maxillofac. Surg. 2005, 34, 391-395. [CrossRef]

23. Bagan, J.V.; Carbonell, F.; Gómez, M.J.; Sánchez, M.; Navarro, A.; Leopoldo, M.; Bagán, L.; Zapater, E. Extra-nodal B-cell non-Hodgkin's lymphomas of the head and neck: A study of 68 cases. Am. J. Otolaryngol. 2015, 36, 57-62. [CrossRef]

24. Oishi, N.; Bagán, J.V.; Javier, K.; Zapater, E. Head and Neck Lymphomas in HIV Patients: A Clinical Perspective. Int. Arch. Otorhinolaryngol. 2017, 21, 399-407. [CrossRef] 